\title{
FIELD ASSESSMENT OF INDUCTION MOTOR EFFICIENCY THROUGH AIR-GAP TORQUE
}

\section{Oak Ridge National Laboratory}

\author{
J. S. Hsu
}

P. L. Sorenson

\section{November 1995}

\author{
DISCLAIMER
}

This report was prepared as an account of work sponsored by an agency of the United States Government. Neither the United States Government nor any agency thereof, nor any of their employees, makes any warranty, express or implied, or assumes any legal liability or responsibility for the accuracy, completeness, or usefulness of any information, apparatus, product, or process disclosed, or represents that its use would not infringe privately owned rights. Reference herein to any specific commercial product, process, or service by trade name, trademark, manufacturer, or otherwise does not necessarily constitute or imply its endorsement, recommendation, or favoring by the United States Government or any agency thereof. The views and opinions of authors expressed herein do not necessarily state or reflect those of the United States Government or any agency thereof.

Prepared by the Oak Ríage ivanonal Laboratory, Uak Kudge, Tennessee, 378sI-7258, managed by Lockheed Martin Energy Systems, for the U.S. Department of Energy under contract DE-AC05-83OR21400.

The submitted manuscript has been authored by a contractor of the U.S. Government under contract No. DE-AC05-84OR21400. Accordingly, the U.S. Government retains a nonexclusive, royalty-free license to publish or reproduce the published form of this contribution, or allow others to do so, for U.S. Government purposes. 


\section{Field Assessment of Induction Motor Efficiency through Air-Gap Torque}

John S. Hsu

Patrick L. Sorenson

\section{Oak Ridge National Laboratory}

This paper suggests the use of air-gap torque to assess efficiency and load changes of induction motors in the field. The efficiency is

$$
\eta=\frac{\left[\begin{array}{l}
\text { (Air gap torque }) \cdot 2 \pi \cdot \frac{(r p m)}{60} \\
-(\text { No load air gap torque }) \cdot 2 \pi \cdot \frac{(r p m)}{60} \\
-(\text { Stray load loss })
\end{array}\right]}{\text { Input power }}
$$

When the supply voltage is unbalanced and contains harmonics, there is a fundamental difference between method $E$ and the air-gap torque method for efficiency assessments. In the real world the supply impedance does change the motor terminal voltages a little as the load varies. The load goes up and further upsets the voltage balance. It results in the increase of the negative sequence voltage. For a low negative sequence voltage a higher negative sequence impedance occurs. This is caused by the non saturated tips of the rotor teeth. The tested data of a 50 Hp motor given in the paper clearly show that the no load negative sequence current of 4.2 Amps is significantly smaller than the negative sequence current of $13.7 \mathrm{Amps}$ at full load. The no load loss does not cover most of the negative sequence losses when the motor is loaded. This is different from what Method $E$ is based on.

Efficiency measurements are conducted on induction motors under situations of normal three-phase, unbalanced three-phase, motor with power-factor-correction capacitors, and motor with single-phase supply, respectively.

Table 1 shows the comparison between calculated and tested values of efficiency and shaft-torque of a $71 / 2 \mathrm{Hp}$ motor under normal three-phase supply. Table 2 shows

\begin{tabular}{|l|l|l|l|}
\hline $\begin{array}{l}\text { Approximate } \\
\text { load }\end{array}$ & & $\begin{array}{l}\text { Shaft torque } \\
\text { [in.Lb] }\end{array}$ & $\begin{array}{l}\text { Efficiency } \\
{[\%]}\end{array}$ \\
\hline \multirow{3}{*}{$100 \%$} & Calculated & 128.2 & 85.9 \\
\cline { 2 - 4 } & Tested & 128.4 & 86.3 \\
\hline \multirow{3}{*}{$75 \%$} & Calculated & 99.9 & 86.2 \\
\cline { 2 - 4 } & Tested & 99.7 & 86.4 \\
\hline \multirow{3}{*}{$50 \%$} & Calculated & 66.1 & 86.1 \\
\cline { 2 - 4 } & Tested & 65.2 & 84.8 \\
\hline \multirow{3}{*}{$0 \%$} & Calculated & 25.9 & 77.5 \\
\cline { 2 - 4 } 0 & Tested & 24.4 & 72.1 \\
\hline \multirow{2}{*}{$0 \%$} & Calculated & 0.9 & 9.8 \\
\cline { 2 - 4 } & Tested & -0.7 & -9.8 \\
\hline
\end{tabular}

Table 1. Comparison between tested and calculated shaft torques and efficiencies of a $71 / 2-\mathrm{Hp}, 2$-pole, 3-phase induction motor.

\begin{tabular}{|l|l|l|l|}
\hline $\begin{array}{l}\text { Approximate } \\
\text { load }\end{array}$ & & $\begin{array}{l}\text { Shaft torque } \\
{[\text { in.Lb] }}\end{array}$ & $\begin{array}{l}\text { Efficiency } \\
{[\%]}\end{array}$ \\
\hline \multirow{3}{*}{$100 \%$} & Calculated & 126.9 & 85.8 \\
\hline \multirow{3}{*}{$75 \%$} & Tested & 126.8 & 85.5 \\
\hline \multirow{3}{*}{$50 \%$} & Calculated & 100.9 & 87.0 \\
\cline { 2 - 4 } & Tested & 99.5 & 85.8 \\
\hline \multirow{3}{*}{$25 \%$} & Calculated & 67.0 & 86.7 \\
\cline { 2 - 4 } & Tested & 65.2 & 85.2 \\
\hline \multirow{3}{*}{$0 \%$} & Calculated & 26.7 & 79.6 \\
\cline { 2 - 4 } & Tested & 24.5 & 72.3 \\
\cline { 2 - 4 } & Calculated & 0.8 & 10.9 \\
\cline { 2 - 4 } & Tested & -0.7 & -9.0 \\
\hline
\end{tabular}

Table 2. Comparison between tested and calculated shaft torques and efficiencies of a 71/2-Hp, 2-pole, 3-phase induction motor under unbalanced voltages.

similar comparison under unbalanced supply situation. Additionally, efficiency field assessments of a $3 / 4 \mathrm{Hp}$ motor under 1) 3-phase motor with power-factor-correction capacitors, and 2) single-phase supply with running capacitor are shown in Figures 1 and 2, respectively. Good agreements are observed in the comparisons.

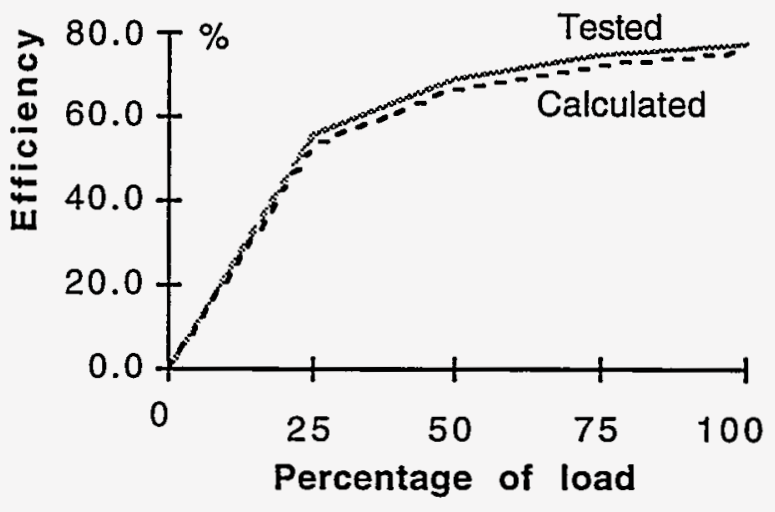

Fig. 1 Efficiency of 3-phase with capacitors situation

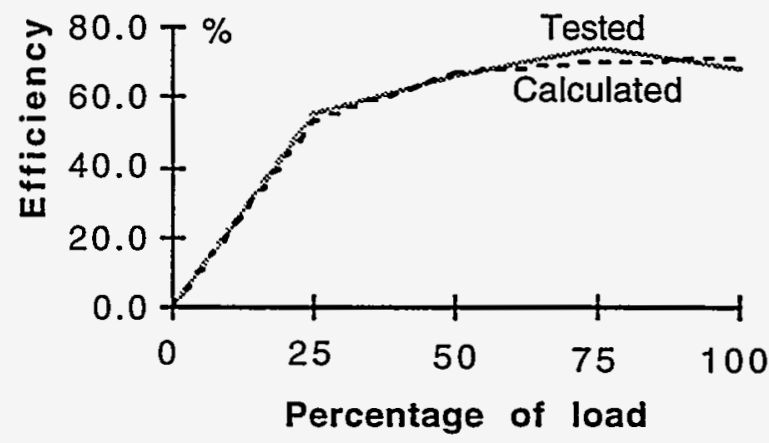

Fig. 2 Efficiency of single-phase-supply situation 


\title{
Field Assessment of Induction Motor Efficiency through Air-Gap Torque
}

\author{
John S. Hsu
}

Patrick L. Sorenson

\author{
Oak Ridge National Laboratory \\ Post Office Box 2003, K-1008-F, MS 7258
}

Oak Ridge, Tennessee 37831-7258

\begin{abstract}
Induction motors are the most popular motors used in industry. This paper further suggests the use of air-gap torque method [1] to evaluate their efficiency and load changes. The fundamental difference between Method $\mathbf{E}$ and the air-gap torque method is discussed. Efficiency assessments conducted on induction motors under various conditions show the accuracy and potential of the air-gap torque method.
\end{abstract}

\section{INTRODUCTION}

Induction motors are the most commonly used motors in industry. They are important components in the chains of drive systems. Motor efficiency is the ratio of shaft output power to motor input power. IEEE Std 112 [2] presents many methods for induction-motor efficiency tests that may not all be suitable for field efficiency assessments.

When the motor is installed in a production system, the no-bench test requirement rules out the use of dynamometer and duplicate-machines approaches.

The equivalent circuit method is commonly used by manufacturers for large rotating machines having greater than NEMA frame sizes. The motor parameters, such as magnetization currents, leakage reactances, resistances, etc., are calculated and correlated with tests for specific voltages. The advantage of equivalent circuit method is the convenience in assessing efficiencies at different slips through its simple circuit calculations. However, tracing parameters of a motor in the field is not an easy task, especially when roughly half the motors used in $U$. S. industry have been rewound [3]. The nominal parameters obtained from manufacturers might not be the same as those under actual motor operating voltage. Ten percent (plus or minus) voltage fluctuations are considered to be acceptable for motors [4]. When the voltage is unbalanced, the equivalent-circuit approach becomes complicated. In addition, it is not uncommon to notice that the power supply in the field is polluted with unbalanced voltages and various harmonic contents that further affect the induction motor efficiency.

Air-gap torque equations have been known for several decades [5-9]. Air-gap torque represents the combined effects of all the flux linkages and currents in both the stator and rotor of the motor. The torque derivation takes the unbalanced supply into consideration. The field test of adjustable-speed-drive efficiency through the air-gap torque method is presented in Ref. [1]. It gives a detailed explanation of the air-gap torque equations.

Fig. 1 shows locations of the input power, Pin, the airgap-torque power, and the output power, Pout. The output power of a motor is the product of the shaft angular speed and shaft output torque. This output torque is the air-gap torque less the torque losses associated with friction, windage, and stray losses caused by rotor currents. The harmonic components of the air-gap torque are different from those of the shaft torque. This difference is caused by the rotor mechanical system.

If the air-gap flux is actually measured, the air-gap torque is evaluated after taking out the core, stator resistance, and stator stray losses. In this paper the air-gap flux is not directly measured. Subsequently, the no-load information and stray load loss data are required.

Unbalanced voltages

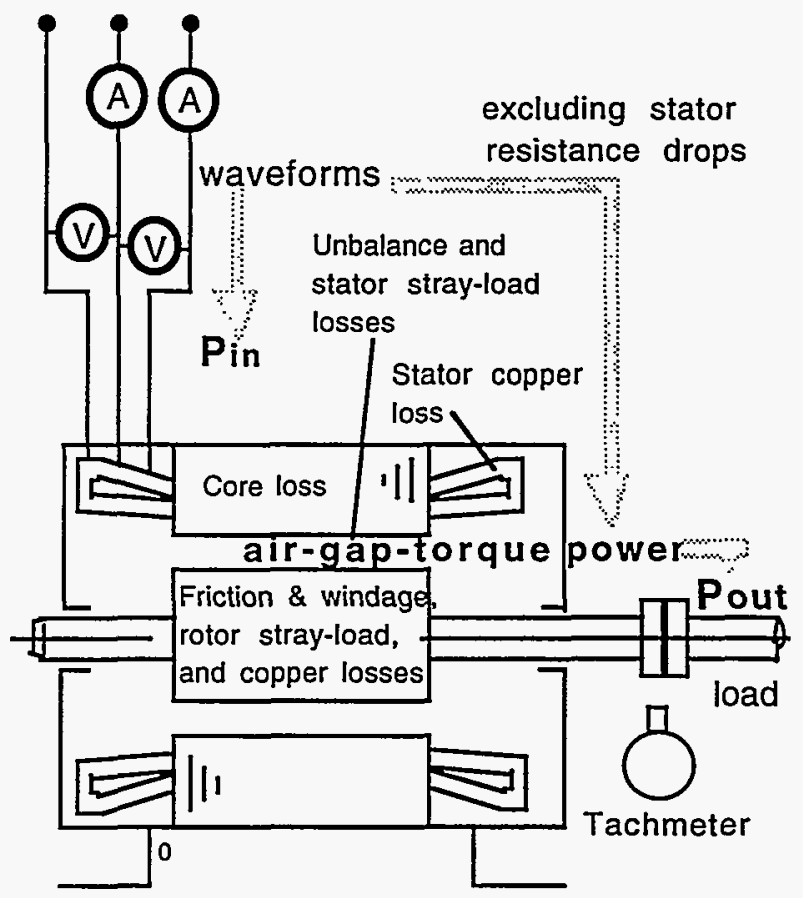

Fig. 1 Locations of input power, air-gap-torque power, and output power 
The air-gap torque method is tested on different size motors and situations to validate this technique. Efficiencies of a $71 / 2 \mathrm{Hp}$ motor under normal three-phase supply and under unbalanced supply situations are assessed and compared with direct torque-gauge measurements. Additionally, efficiency field assessments of a $3 / 4 \mathrm{Hp}$ motor under three different situations are conducted. The different situations are: 1) 3-phase motor alone, 2) 3-phase motor with power-factor-correction capacitors, and 3) single-phase supply with running capacitor.

\section{Fundamental Difference between Method E and AIR-GAP TORQUE METHOD}

The input power of a three-phase induction motor is the average summation of products of the instantanecus phase voltages, $v_{a}, v_{b}, v_{c}$, and phase currents, $i_{a}, i_{b}$, and $i_{c}$.

Power $=\frac{\int_{0}^{\text {period }}\left(v_{a} i_{a}+v_{b} i_{b}+v_{c} i_{c}\right) d t}{(\text { period })}$

The air-gap torque equation is

$$
\text { Torque }[N m]=\frac{P}{2 \cdot \sqrt{3}}\left\{\begin{array}{c}
\left.{ }^{(i A}-i_{B}\right) \cdot \int\left[\nu C A-R\left(i C-i_{A}\right)\right] d t \\
-\left({ }^{C} C-i_{A}\right) \cdot \int\left[v_{A B}-R\left(i_{A}-i_{B}\right)\right] d t
\end{array}\right\}
$$

where

$$
\begin{aligned}
P & =\text { number of poles } \\
i_{A}, i_{B}, \text { and } i_{C} & =\text { line currents } \\
R & =\begin{array}{l}
\text { half of the line-to-line resistance } \\
\text { value. }
\end{array}
\end{aligned}
$$

When the balanced power supply contains negligible harmonics, various modified versions based on Method E1 of the IEEE 112 standard [2] can be quite accurate for conventional induction motor field efficiency assessments. The waveforms acquired by the air-gap torque method may be used to calculate the power and harmonic content in detail. However, this is not the most important difference between the air-gap torque method and Method E. The fundamental difference between these two methods is as follows.

There is an unrealistic expectation on Method E, which suggests that under any load situation of a motor, the losses produced by the negative fields associated with unbalanced supply voltages and harmonics are included in the no-load loss. These negative sequence fields are not changed at either full load or no load, because the speed difference between full load and no load is small. Consequently, the slip is practically not changed, and the negative sequence impedance as well as the negative sequence currents remain the same. Under any load the loss associated with the negative sequence fields is the same as this loss at no load. Therefore, the effects of unbalanced voltages and harmonics are fully covered in Method E.

The air gap torque method does not consider that this expectation is correct for motors operating in the field. In the real world there is supply impedance. The motor terminal voltages do change a little as the load varies. Table 1 shows the tested fundamental frequency voltages and currents of the positive and negative sequence components under an unbalanced supply. When the load goes up and further upsets the voltage balance, the negative sequence voltage increases. The varied ratios of negative sequence voltages to currents indicate that the negative sequence impedance is not a constant. It goes up when the negative sequence current goes down. For a small negative sequence current a higher negative sequence impedance occurs. This is caused by the non saturated tips of the rotor teeth. The tested data clearly show that the no load negative sequence current of $4.2 \mathrm{Amps}$ is significantly smaller than the negative sequence current of 13.7 Amps at full load. The no load loss does not cover most of the negative sequence losses when the motor is loaded.

\begin{tabular}{|c|c|c|c|c|c|}
\hline \multirow{2}{*}{ Load } & \multicolumn{2}{|c|}{$\begin{array}{c}\text { Positive } \\
\text { Sequence. }\end{array}$} & \multicolumn{2}{c|}{$\begin{array}{c}\text { Negative } \\
\text { Sequence }\end{array}$} & \multirow{2}{*}{ Ratio } \\
\cline { 2 - 5 } & $\begin{array}{c}\text { V+ } \\
{[\mathrm{V}]}\end{array}$ & $\begin{array}{c}\text { I+ } \\
{[\mathrm{Amp}]}\end{array}$ & $\begin{array}{c}\text { V- } \\
{[\mathrm{V}]}\end{array}$ & $\begin{array}{c}\text { I- } \\
{[\text { Amp] }}\end{array}$ & V-I- \\
\hline $100 \%$ & 451.5 & 60.0 & 20.9 & 13.7 & 1.53 \\
\hline $75 \%$ & 452.8 & 43.7 & 20.8 & 12.8 & 1.62 \\
\hline $50 \%$ & 454.2 & 30.8 & 20.4 & 11.5 & 1.78 \\
\hline $25 \%$ & 455.4 & 19.0 & 18.7 & 8.6 & 2.17 \\
\hline $0 \%$ & 457.9 & 12.2 & 16.0 & 4.2 & 3.81 \\
\hline
\end{tabular}

Table 1 Tested fundamental frequency positive and negative sequence components of voltages and currents of a $50 \mathrm{Hp}$ motor under an unbalanced supply.

In Method $\mathrm{E}$ the input power is used as the base to subtract various losses for the output power. The negative sequence losses that are mostly not covered by the no load loss increase the input power. Subsequently, the output power is higher. On the contrary, the air-gap torque method uses the air-gap torque power, not the input power, as the starting point of loss subtraction for the output power evaluation. The losses associated with negative sequence currents are calculated for each load. The air-gap torque method recognizes the sign difference between the torque and the corresponding input power. For example: the input power of the fundamental negative sequence voltage and currents is positive, but the air-gap torque is negative. The air gap torque power further subtracts the estimated stray load loss and the no load air gap torque power that includes the friction and windage loss and the core loss for the output power.

The assumption of neglecting winding spatial harmonics in the air-gap torque method is acceptable when the fifth and seventh spatial harmonics are negligibly small through distributed windings with a proper coil pitch. However, their effects need to be studied further.

\section{INPUT Power AND AIR-GAP TORQUe FOR THREE-LEAD MOTORS}

Three-lead motor are often used for NEMA-frame-size motors. The power and air-gap torque equations can be further simplified.

\section{A. Input power of 3-lead motors}

The input power of an induction motor with 3 leads 
can be obtained through a two wattmeter circuitry. The instantaneous power of each pair of leads is the product of its current and voltage. Input power is the average power of the sum of the instantaneous powers of the two pairs of leads over the measured period of time.

\section{B. Air-Gap Torque}

The air-gap-torque equation for 3-lead motors is given in Reference [1]. Only two line voltages and two line currents are required for the air-gap torque calculation.

\section{Efficiency Equations}

The shaft output power is calculated from the shaft

speed (rpm) and shaft torque.

$$
\text { Output power }=(\text { Shaft torque }) \cdot 2 \pi \cdot \frac{(r p m)}{60}
$$

where the shaft torque is

$$
\begin{aligned}
& \text { Shaft torque }=(\text { Air gap torque }) \\
& -(\text { No load air gap torque })-\frac{(\text { Stray load loss })}{2 \pi \cdot \frac{(r p m)}{60}}
\end{aligned}
$$

When the shaft speed, rpm, is used for calculating the air gap torque power for all the torque components contained in the air gap torque, the slip losses are excluded in the first and second terms of (5).

The negative sequence losses are taken into consideration by subtracting the negative air gap torque power and by excluding the slip losses at each load point. The no load air gap torque power that represents the friction and windage loss and the no-load core loss is assumed as a constant throughout the entire load region.

Under load situations the stray-load loss can be assumed as a certain percentage according to the machine ratings given in the IEEE 112 [1]. These percentages are given in Table 2. The experimental samples in this paper use the values given in the Table.

For other than rated load, the stray load loss for the experimental motors is assumed to be proportional to the square of the difference of the air gap torque power and the no load air gap torque power.

From (3), (4), and the definition of efficiency, the

\begin{tabular}{|l|l|}
\hline \multicolumn{1}{|c|}{ Machine Rating } & $\begin{array}{l}\text { Stray-Load loss } \\
\text { percentage of rated } \\
\text { outbut }\end{array}$ \\
\hline $1-125 \mathrm{hp}$ & $1.8 \%$ \\
\hline $126-500 \mathrm{hp}$ & $1.5 \%$ \\
\hline $501-2499 \mathrm{hp}$ & $1.2 \%$ \\
\hline $2500 \mathrm{hp}$ and greater & $0.9 \%$ \\
\hline
\end{tabular}

Table 2. IEEE 112 Assumed Values of Stray-Load efficiency, $\eta$, yields

$$
\eta=\frac{\left[\begin{array}{l}
(\text { Air gap torque }) \cdot 2 \pi \cdot \frac{(r p m)}{60} \\
-(\text { No load air gap torque }) \cdot 2 \pi \cdot \frac{(r p m)}{60} \\
-(\text { Stray load loss })
\end{array}\right]}{\text { Input power }}
$$

\section{ASSESSMENT OF EFFICIENCY}

\section{A. Experimental Setup}

Experimental setup is shown in Fig. 2. As it is mentioned earlier, for 3-lead induction motors only two line currents and two line voltages are needed for the air-gap torque calculation. The numbers of data points per cycle of 84 and 835 have been used respectively. Normally, five cycles of data would give a better average picture. Under an exceptionally stable supply and load condition, one cycle of data might do the job. The higher number of data points per cycle gives more accurate result. This can be examined by comparing the discrepancies of numerical flux integrations [1] between two approaches; one is from the total values of currents and voltages, and the other one is from the Fourier components of the total values. For the lower number of data points, breaking the total values into various frequency components before integration for flux gives more accurate results.

Isolated current and voltage transducers are used. Isolated transducers are advantageous since the signals can be connected to a single common point. This is a great convenience to the data acquisition system provided that

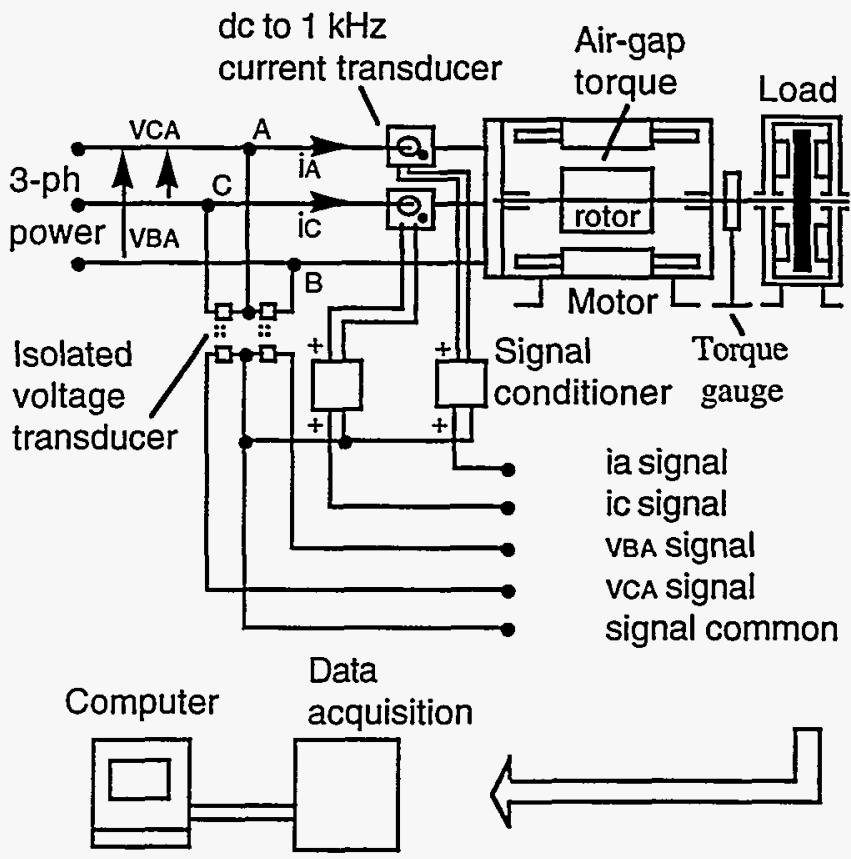

Fig. 2 Efficiency assessment setup for air-gap torque method 


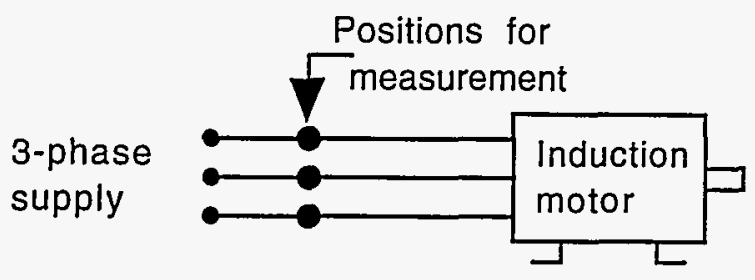

(a) 3-phase induction motor with normal or unbalanced voltages

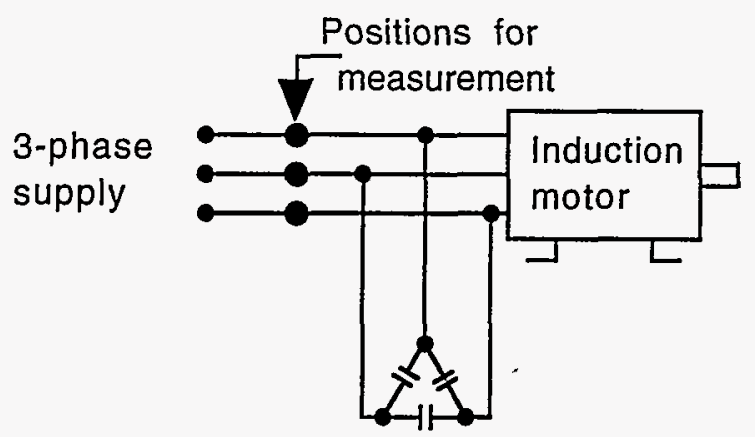

(b) 3-phase induction motor with capacitors

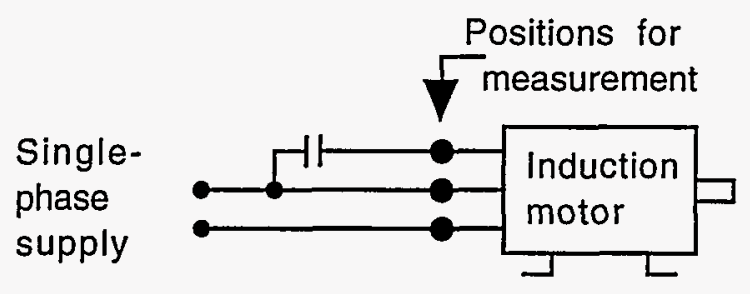

(c) Single-phase induction motor

Fig. 3 Induction motor under various situations

additional instrumentation errors are negligible.

A four-channel, dc to $175 \mathrm{MHz}$, digital storage scope is used. It has a GPIB (IEEE488) input/output interface capability. Maximum sample rate is 100 megasample per

\begin{tabular}{|l|l|l|l|}
\hline $\begin{array}{l}\text { Approximate } \\
\text { load }\end{array}$ & & $\begin{array}{l}\text { Shaft torque } \\
\text { [in.Lb] }\end{array}$ & $\begin{array}{l}\text { Efficiency } \\
{[\%]}\end{array}$ \\
\hline \multirow{3}{*}{$100 \%$} & Calculated & 128.2 & 85.9 \\
\cline { 2 - 4 } & Tested & 128.4 & 86.3 \\
\hline \multirow{3}{*}{$75 \%$} & Calculated & 99.9 & 86.2 \\
\cline { 2 - 4 } & Tested & 99.7 & 86.4 \\
\hline \multirow{3}{*}{$50 \%$} & Calculated & 66.1 & 86.1 \\
\cline { 2 - 4 } $25 \%$ & Tested & 65.2 & 84.8 \\
\hline \multirow{3}{*}{$0 \%$} & Calculated & 25.9 & 77.5 \\
\cline { 2 - 4 } & Tested & 24.4 & 72.1 \\
\hline & Calculated & 0.9 & 9.8 \\
\cline { 2 - 4 } & Tested & -0.7 & -9.8 \\
\hline
\end{tabular}

Table 3 Comparison between tested and calculated shaft torques and efficiencies of a 71/2-Hp, 2-pole, 3-phase induction motor.
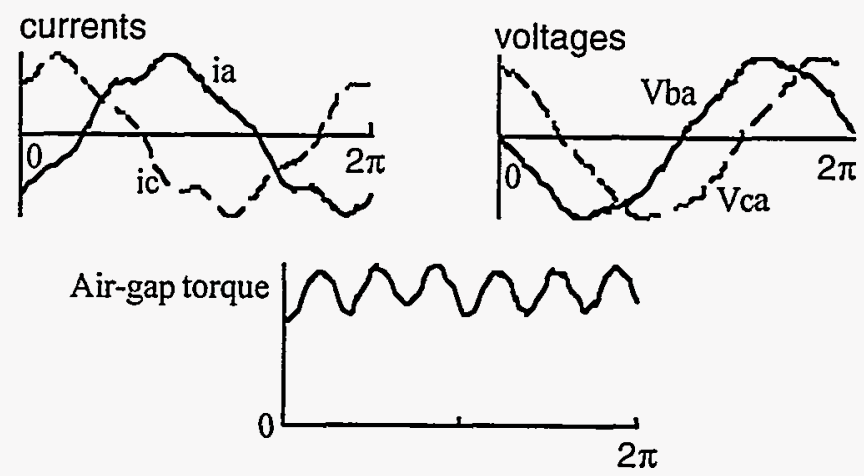

(a) Normal (basically balanced) supply voltages
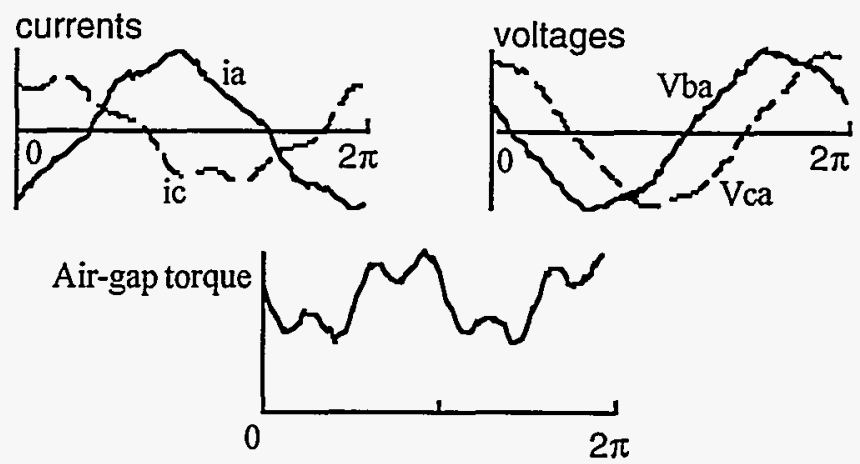

(b) Unbalanced supply voltages

Fig. 4 Currents, voltages, and air-gap torques of a 3-phase induction motor

second, per channel at $5 \mathrm{~ms} / \mathrm{div}$. Its storage capacity is $4 \times 10 \mathrm{k}$. The minimum required sample rates is affected by the number of data point per cycle of a measured datum and the number of data to be measured.

Sample time differences among different channels are neglected in this study. This can be included easily if the specific time differences are given. However, when the time increment for sampling is small, the error relating to the time differences is negligible.

\section{B. Efficiency Assessments of Induction Motors Under Various Situations}

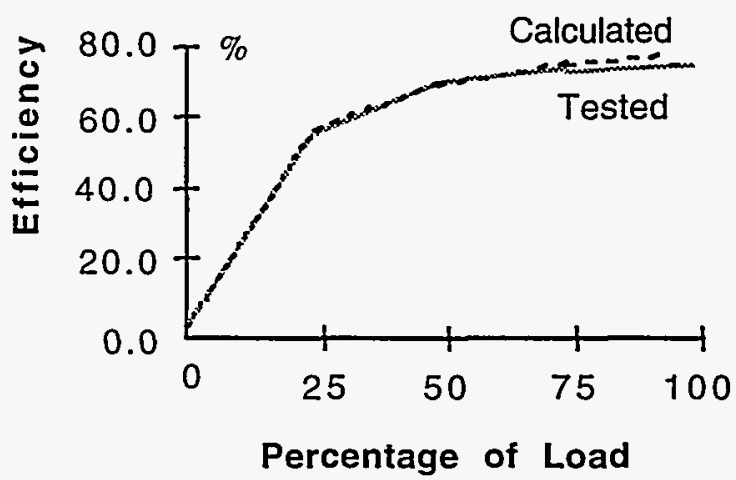

Fig. 5 Efficiency of normal 3-phase situation 
Fig. 3 shows various situations for field assessments of efficiency. They are described as follows.

1. Three-phase induction motor with normal (or basically balanced) supply voltages:

A. 71/2- $\mathrm{Hp}, 60-\mathrm{Hz}, 2$-pole induction motor is tested under the situation shown in Fig. 3a. Two input voltages, two line currents, and the calculated air-gap torque are shown in Fig. 4a. The comparison between calculated results of the air gap torque method and the tested results obtained from torque-gauge tests is given in Table 3. Good shaft torque agreement is observed. When the motor is lightly loaded, a small discrepancy in the torque between calculated and tested results gives a large discrepancy between the efficiency values.

Similar comparison of results for a 3/4-Hp, 4-pole, 60 $\mathrm{Hz}$ induction motor is shown in Fig. 5. During no-load test the motor shaft of the $3 / 4 \mathrm{Hp}$ motor is still coupled to a small load of the eddy current disk, this small load is assumed to be $25 \%$ of the no load air gap torque.

2. Three-phase induction motor with unbalanced voltages:

The same $71 / 2-\mathrm{Hp}, 60-\mathrm{Hz}, 2$-pole induction motor is tested with unbalanced voltages under the situation shown in Fig. 3a. The two line currents presented in Fig. $4 \mathrm{~b}$ are

\begin{tabular}{|l|l|l|l|}
\hline $\begin{array}{l}\text { Approximate } \\
\text { load }\end{array}$ & & $\begin{array}{l}\text { Shaft torque } \\
{[\text { in.Lb] }}\end{array}$ & $\begin{array}{l}\text { Efficiency } \\
{[\%]}\end{array}$ \\
\hline \multirow{3}{*}{$100 \%$} & Calculated & 126.9 & 85.8 \\
\cline { 2 - 4 } & Tested & 126.8 & 85.5 \\
\hline \multirow{3}{*}{$75 \%$} & Calculated & 100.9 & 87.0 \\
\cline { 2 - 4 } & Tested & 99.5 & 85.8 \\
\hline \multirow{3}{*}{$50 \%$} & Calculated & 67.0 & 86.7 \\
\cline { 2 - 4 } $25 \%$ & Tested & 65.2 & 85.2 \\
\hline \multirow{3}{*}{$0 \%$} & Calculated & 26.7 & 79.6 \\
\cline { 2 - 4 } & Tested & 24.5 & 72.3 \\
\hline & Calculated & 0.8 & 10.9 \\
\cline { 2 - 4 } & Tested & -0.7 & -9.0 \\
\hline
\end{tabular}

Table 4 Comparison between tested and calculated shaft torques and efficiencies of a 71/2-Hp, 2-pole,

3 -phase induction motor under unbalanced voltages.

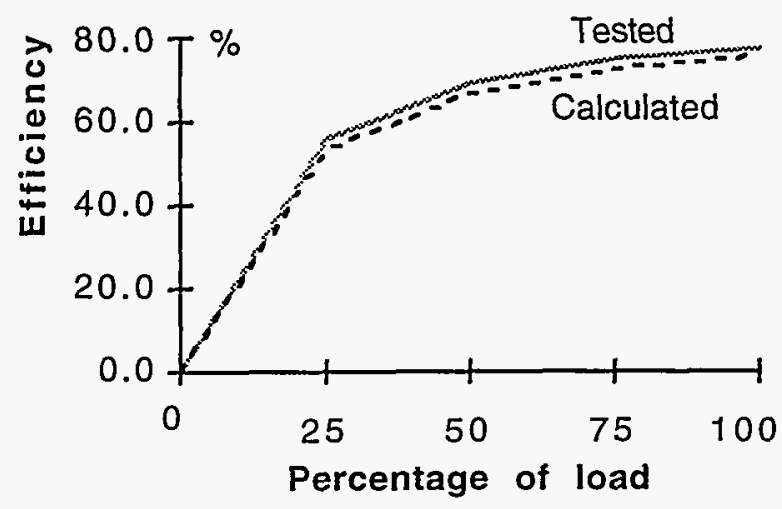

Fig. 6 Efficiency of 3-phase with capacitors situation quite different due to the unbalanced voltages. There is a significant second order torque harmonic in the air-gap torque shown in Fig. 4b. This method can also be used for stator shorted turn detection given in Ref. [7].

The comparison between calculated results of the air gap torque method and the tested results obtained from torquegauge tests is given in Table 4. Again, good agreements are shown in both the shaft torques and efficiencies.

\section{Three-phase induction motor with capacitors:}

When the position for measurement, as shown in Fig. $3 \mathrm{~b}$, is located before the capacitors, the proposed method still can be used with expected minor errors associated with a lower voltage drop on stator resistances. This is caused by the lower line currents due to the power-factorcorrection capacitors.

Fig. 6 shows the comparison between tested and calculated efficiencies of a 3/4-Hp, 3-phase, 208-volt, 4pole induction motor. Three 14-microfarad capacitors connected in delta are used for the power-factor correction. Acceptable results are obtained.

\section{Single-phase induction motor:}

This refers to a single-phase supply situation of a threephase induction motor with one phase connected through a 14-microfarad running capacitor. Fig. 7 shows the comparison between tested and calculated efficiencies of a 3/4-Hp, 3-phase, 208-volt, 4-pole induction motor connected according to Fig. 3c. Again, acceptable results are observed.

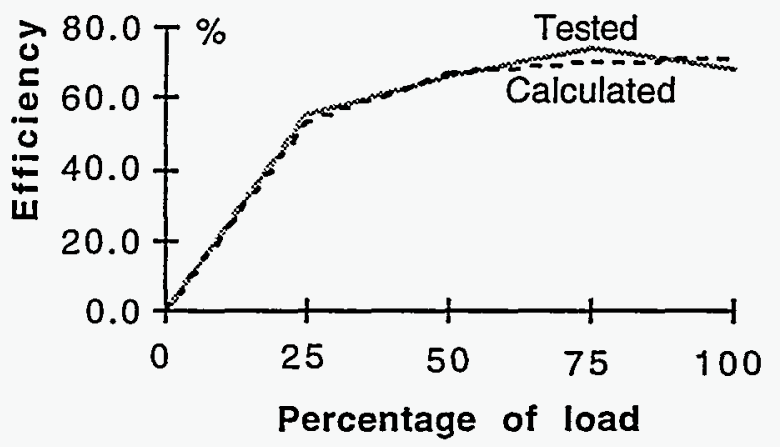

Fig. 7 Efficiency of single-phase-supply situation

\section{CONCLUSIONS}

1. This paper presents a study on the use of air-gap torque method to assess efficiencies and the load changes of induction motors. 
2. The power supply in the field is commonly polluted with unbalanced supply voltages and harmonics that produce negative sequence or asynchronous fields. An example shows that in the real world the power supply has impedance, the loss associated with negative sequence fields cannot be correctly represented by the no load loss.

3. In the air-gap torque method, the air-gap torque power, not the input power, is the starting point for loss subtraction. When there are harmonics or negativesequence voltages and currents, the air-gap torque method considers the slip losses and recognizes the sign difference between the torque and the corresponding input power. Subsequently, the harmonic and fundamental negative sequence effects on efficiency can be more accurately assessed.

4. Efficiency assessments conducted on induction motors under conditions of normal three-phase, unbalanced three-phase, motor with power-factor-correction capacitors, and motor with single-phase supply, respectively, show good results.

\section{ACKNOWLEDGMENTS}

The authors would like to thank the Office of Energy Efficiency and Renewable Energy, U.S. Department of Energy, for partial financial support through the Motor Challenge Program. Thanks are due to the Oak Ridge National Laboratory (ORNL) for the support staff and facilities provided for the research work. The authors would like to express their appreciation to Paul Scheihing, DOE program manager, Mitchell Olszewski, ORNL program manager, and Donald Adams, group manager, for their support in this research as well. Appreciation is also extended to John Kueck, Leon Tolbert, and Pedro Otaduy for their independent tests conducted for Tables 3 and 4. The assistance from George Ott, superintendent of Power Electronics Laboratory, is gratefully acknowledged.

\section{REFERENCES}

[1] Hsu (Htsui), John S., Scoggins, Brian P., "Field Test of Motor Efficiency and Load Changes through Air-Gap Torque," IEEE Transactions on Energy Conversion., September 1995, Vol. 10, No. 3, ITCNE4 (ISSN 08858969), pp. 471-77.

[2] IEEE Standard Test Procedure for Polyphase Induction Motors and Generators, IEEE Std 112-1991, IEEE Power Engineering Society, New York, NY.

[3] R. L. Nailen, "Can Field Tests Prove Motor Efficiency?' IEEE Conference Record of Industrial and Commercial Power Systems Technical Conference, 1988 May 2-5, Baltmore, MD, pp.110-116.

[4] NEMA MG-1, Part 12, Page 13, NEMA. Washington DC, 1993.

[5] Jing-Tak Kao, ANALYSES OF TRANSIENTS AND OPERATIONS OF ALTERNATING-CURRENT MACHINES, Second Edition, Science Press, Beijing, China. Sept. 1964.

[6] J.O. Ojo, V. Ostovic, T.A. Lipo, and J.C. White. "Measurement and Computation of Starting Torque Pulsations of Salient Pole Synchronous Motors," IEEE/PES 1989 Summer Meeting, Long Beach, California. July 9-14,
1989. Paper No. 89 SM 756-8 EC

[7] Hsu, John S., "Monitoring of Defects in Induction Motors through Air-Gap Torque Observation," IEEE Transactions on Industrv Applications, September 1995, Vol. 31, No. 5, ITIACR, (ISSN 0093-9994), pp. 1016-21.

[8] J.S. Hsu (Htsui), A.M.A. Amin, "Torque Calculations of Current-Source Induction Machines Using the 1-2-0 Coordinate System," IEEE Transactions on Industrial Electronics, vol. 37, no. 1, February 1990, pp. $34-40$.

[9] J.S. Hsu, H.H. Woodson, and W.F. Weldon, "Possible Errors in Measurement of Air-Gap Torque Pulsations of Induction Motors," IEEE Transactions on Energy Conversion, (Paper No. 91 SM 390-5 EC)

[10] J. C., Hirzel, "Efficiency Measurement and Evaluation of Existing Motors," Record of Conference Papers, 30th Annual Petroleum and Chemical Industry Conference, pp.227-30, IEEE New York, N. Y.

[11] Robert E. Oesterlei, " Motor Efficiency Test MethodsApple and Oranges?" Power Transmission Design, 22 (5); pp. 41-43, May 1980

[12] Hsu (Htsui), John S., Otaduy, Pedro J., Kueck, John D., "Efficiency and Reliability Assessments of Retrofitted High-Efficiency Motors," Conference Record of 1995 IEEE 30th IAS Annual Meeting, October 1995, Orlando, Florida, pp. 2745-51.

John S. Hsu (Htsui) (SM '89) was born in China. He received a B.S. degree from Tsing-Hua University, Beijing, China, and a Ph.D. degree from Bristol University, England. He joined the Electrical and Electronics Engineering Department of Bradford University, England, serving there for nearly two years.

After his arrival in the United States, he worked in research and development areas for Emerson Electric Company and later for Westinghouse Electric Corporation. $\mathrm{He}$ established the technical innovations for the Westinghouse World Series motors. Many of his design programs are currently used by industry.

He served as head of the Rotating Machines and Power Electronics Program, Center for Energy Studies, the University of Texas at Austin for over four years. Presently, he is a task leader and a senior staff scientist of the Digital and Power Electronics Group, ORNL.

Patrick L. Sorenson is a junior attending North Dakota State University majoring in Electrical Engineering. He is a permanent member of the National Honor Society and has received several academic scholarships. He has served as Treasurer of the NDSU Chapter of IEEE and continues to stay active in the organization.

Mr. Sorenson is currently participating in the Science and Engineering Research Semester at the ORNL sponsored by Oak Ridge Associated Universities and the Department of Energy. Mr. Sorenson enjoys football and baseball as well as coaching youth hockey.

* The submitted manuscript has been authored by Oak Ridge National Laboratory, Oak Ridge, Tennessee 37831-7280. managed by Lockheed Martin Energy Systems, Inc. for the U. S. Department of Energy under contract No. DE-AC05-840R2!400. Accordingly, the U. S. Government retains a nonexclusive, royalty-free license to publish or reproduce the published form of this contribution, or allow others to do so, for U. S. Government purposes. 